\title{
Effects of 108 Days Tritium Exposure on UHMW-PE, PTFE, and Vespel(R)
}

by

E. A. Clark

Westinghouse Savannah River Company

Savannah River Site

Aiken, South Carolina 29808

K. L. Shanahan

M. J. Pechersky

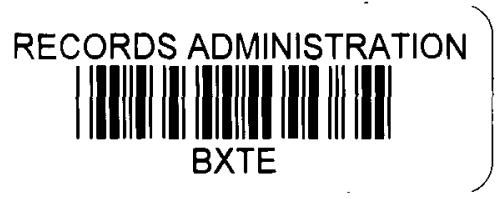

DOE Contract No. DE-AC09-96SR18500

This paper was prepared in connection with work done under the above contract number with the U. S.

Department of Energy. By acceptance of this paper, the publisher and/or recipient acknowledges the U. S. Government's right to retain a nonexclusive, royalty-free license in and to any copyright covering this paper, along with the right to reproduce and to authorize others to reproduce all or part of the copyrighted paper. 


\title{
EFFECTS OF 108 DAYS TRITIUM EXPOSURE ON UHMW-PE, PTFE, AND VESPEL ${ }^{\circledR}$
}

\author{
Elliot A. Clark, Kirk L. Shanahan, Martin J. Pechersky
}

16 October 2002 
This document was prepared in conjunction with work accomplished under Contract No. DE-AC09-96SR18500 with the U. S. Department of Energy.

\section{DISCLAIMER}

This report was prepared as an account of work sponsored by an agency of the United States Government. Neither the United States Government nor any agency thereof, nor any of their employees, makes any warranty, express or implied, or assumes any legal liability or responsibility for the accuracy, completeness, or usefulness of any information, apparatus, product or process disclosed, or represents that its use would not infringe privately owned rights. Reference herein to any specific commercial product, process or service by trade name, trademark, manufacturer, or otherwise does not necessarily constitute or imply its endorsement, recommendation, or favoring by the United States Government or any agency thereof. The views and opinions of authors expressed herein do not necessarily state or reflect those of the United States Government or any agency thereof.

This report has been reproduced directly from the best available copy.

Available for sale to the public, in paper, from: U.S. Department of Commerce, National Technical Information Service, 5285 Port Royal Road, Springfield, VA 22161, phone: (800) 553-6847, fax: (703) 605-6900

email: orders@ntis.fedworld.gov

online ordering: http://www.ntis.gov/help/index.asp

Available electronically at http://www.osti.gov/bridge

Available for a processing fee to U.S. Department of Energy and its contractors, in paper, from: U.S. Department of Energy, Office of Scientific and Technical Information, P.O. Box 62, Oak Ridge, TN 37831-0062,

phone: (865)576-8401,

fax: (865)576-5728

email: $\underline{\text { reports@ adonis.osti.gov }}$ 
SMTD

STRATEGIC MATERIALS TECHNOLOGY DEPARTMENT

$\begin{array}{ll}\text { Keywords: } & \text { Tritium } \\ & \text { Polymers } \\ & \text { Radiation Damage }\end{array}$

Retention: Permanent

\title{
Effects of 108 Days Tritium Exposure on UHMW-PE, PTFE and Vespel®
}

\author{
Elliot A. Clark ${ }^{*}$, Kirk L. Shanahan ${ }^{\#}$, Martin J. Pechersky ${ }^{*}$ \\ "Materials Technology Section \\ "Hydrogen Technology Section
}

ISSUED: $\quad 16$ October 2002

Unclassified

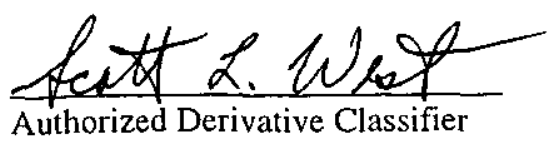

$\frac{11 / 4 / 2002}{\text { Date }}$ 
THIS PAGE INTENTIONALLY LEFT BLANK 
WSRC-TR-2002-00477

EFFECTS OF 108 DAYS TRITIUM EXPOSURE ON UHMW-PE, PTFE AND VESPEL ${ }^{\circledR}$

\section{CONTENTS}

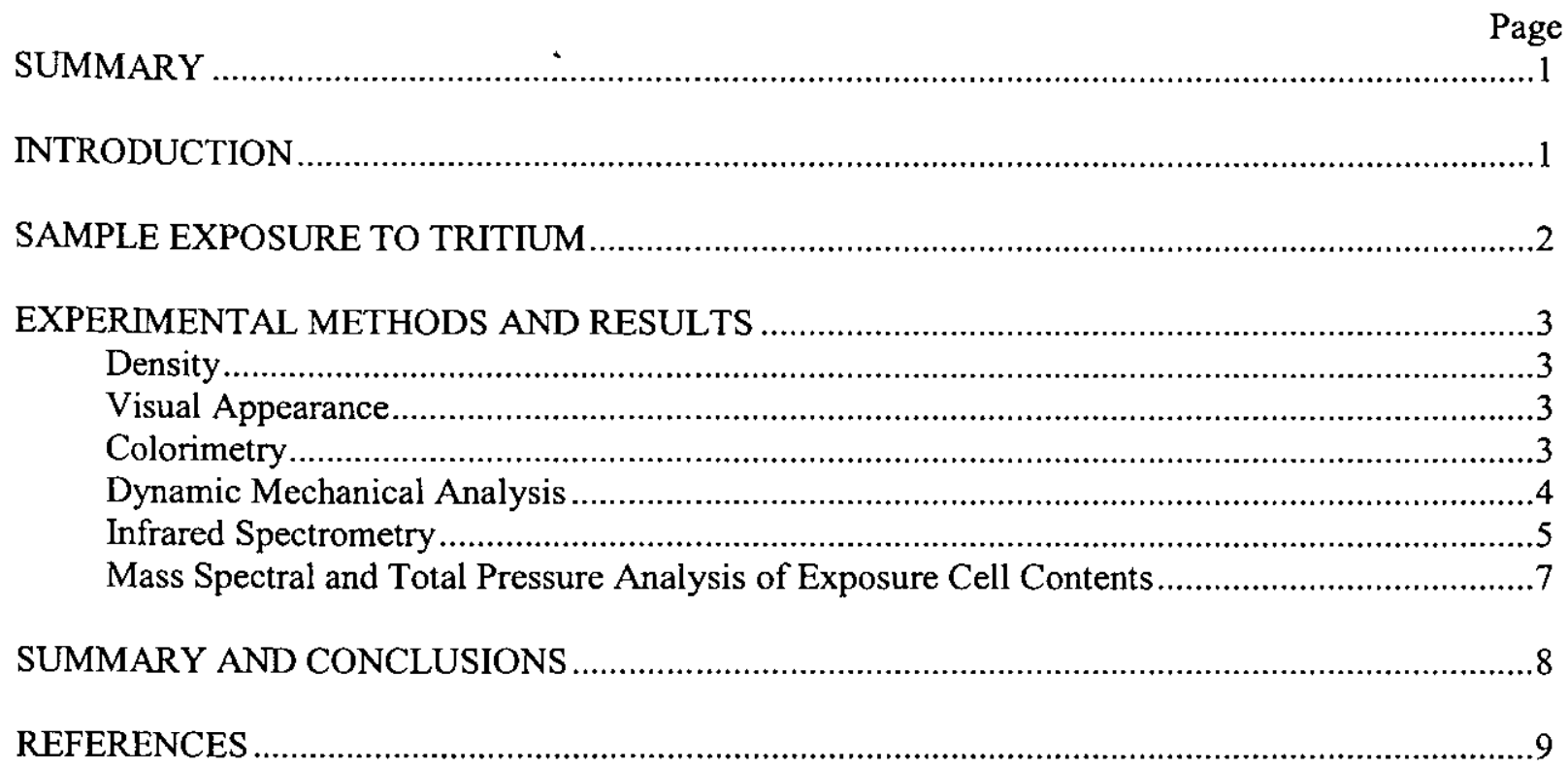

\section{TABLE}

I. Mass Spectroscopic Analysis and Total Pressure Results........................................................ 


\section{FIGURES}

1. Density of UHMW-PE, PTFE, and Vespel® before and after exposure to 1 atm. Tritium gas

for 108 days.....

2. Colorimetry data for unexposed samples and samples exposed for 108 days to 1 atmosphere tritium

3. 1931 CIE chromaticity diagram, indicating color change of PTFE

4. Storage modulus, loss modulus, and tan delta for UHMW-PE sample exposed to 108 days of tritium at 1 atmosphere, and an unexposed sample.

5. Storage modulus, loss modulus, and tan delta as a function of tempcrature for PTFE sample exposed to 1 atmosphere tritium for 108 days, and an unexposed sample.

6. Storage modulus, loss modulus, and tan delta as a function of temperature for Vespel® sample exposed to 1 atmosphere tritium for 108 days, and an unexposed sample

7. Representative ZnSe ATR FT-IR spectra (\% transmittance versus wavenumber) from unexposed and tritium exposed UHMW-PE

8. Representative spectra (\% transmittance versus wavenumber) from different locations on the same 108 day exposed UHMW-PE sample.

9. Representative spectra (\% transmittance versus wavenumber) unexposed and tritium exposed PTFE sample

10. Representative spectra (\% transmittance versus wavenumber) from different locations on the same 108 day exposed PTFE sample

11. Representative ZnSe ATR FT-IR spectra (\% transmittance versus wavenumber) from unexposed and tritium exposed Vespel $($......

12. Representative spectra (\% transmittance versus wavenumber) from different locations on the same 108 day Vespel® sample.

13. Vespel $\circledast$ monomer unit chemical structure

14. Computed sample cell pressure and measured cell hydrogen content versus aging time 19 


\title{
EFFECTS OF 108 DAYS TRITIUM EXPOSURE ON UHMW-PE, PTFE AND VESPEL $^{\circledR}$
}

\author{
Elliot A. Clark, Kirk L. Shanahan, Martin J. Pechersky
}

\section{$\underline{\text { SUMMARY }}$}

Samples of three polymers, Ultra-High Molecular Weight Polyethylene (UHMW-PE), polytetrafluoroethylene (PTFE, also known as Teflon ${ }^{\circledR}$ ), and Vespel@ polyimide were exposed to 1 atmosphere of tritium gas at ambient temperature for 108 days. Sample mass and size measurements to calculate density, spectra-colorimetry, dynamic mechanical analysis (DMA), and Fourier-transform infrared spectroscopy (FT-IR) were employed to characterize the effects of this exposure on these samples. Changes of the tritium exposure gas itself were characterized by total pressure and by mass spectroscopic analysis of the exposure atmosphere. Both DMA and FT-IR indicate that UHMW-PE exposed to tritium initially crosslinks and becomes stiffer. PTFE shows evidence of both crosslinking and chain scission, resulting in a stiffer material but additional molecular groups that dissipate mechanical energy and absorb infrared radiation. Vespel[ shows little effect of tritium exposure in both DMA and FT-IR tests. The density of UHMW-PE increased by about $2.3 \%$ and that of Vespelß increased $4.4 \%$, and the density of PTFE decreased by about $2.7 \%$. The color of UHMW-PE changed from white to purple, that of PTFE changed from white to slightly gray, and the color of Vespel ${ }^{\circledR}$ was unchanged. Color measurements using a spectracolorimeter quantified the color changes. Analysis of the pressure and chemical composition of the exposure gas, along with FT-IR spectra, reveals that tritium isotopically exchanges with protium in the polymers. Protium is found in the exposure gas for all three polymers (surprising for PTFE). Low molecular weight carbon species were found, but at very low levels in all cases. There was an unanticipated net increase of exposure gas pressure for UHMW-PE, and a net decrease for PTFE and Vespel®. These data will be used with similar data that will be collected at regular intervals after continued exposure time to investigate the property changes of these polymers with time.

\section{INTRODUCTION}

Polymers are known to have a limited life when exposed to ionizing radiation while metals have a much longer service life in tritium processing systems in applications contacting high concentrations of tritium. However, there are inevitably specific applications for which polymers are uniquely suited and the limited life of polymers in these situations can be mitigated by materials selection and by regular maintenance and replacement. In the Building 233-H tritium facility at SRS, the stem tips of the Seismic Tritium Confinement System (STCS) valves are made of Ultra-High Molecular Weight polyethylene (UHMW-PE). UHMW-PE is an excellent choice for this application because of its outstanding impact and abrasion resistance. Initially the lifetime of this stem tip was estimated to be five years, however the actual lifetime in the facility was found to be far less (one or two years), based on regular valve tests. Because of the unexpectedly short lifetime, funding for a research program to study tritium effects on polymers was initiated to provide the technical basis for the lifetime of UHMW-PE stem tips in particular, and to advance understanding of the behavior of polymers exposed to tritium in general. This technical report is the first report from this research program.

Three materials have been chosen for study: UHMW-PE, polytetrafluoroethylene (PTFE, also known as Teflon®), and Vespel® polyimide. Vespel® is a modern engineered material (manufactured by Du Pont) that has outstanding high temperature properties and that has been successfully employed as valve stem tips in tritium systems at Los Alamos National Laboratory. PTFE is known to degrade when exposed to tritium, and so is included in this study to provide a basis for comparison of property changes with time.

When polymers are exposed to ionizing radiation, highly reactive "free radical" groups form from the absorption of the ionizing photon or particle (for example gamma ray, alpha particle, or beta particle 
When polymers are exposed to ionizing radiation, highly reactive "free radical" groups form from the absorption of the ionizing photon or particle (for example gamma ray, alpha particle, or beta particle (tritium)) [1]. These reactive groups further react, and the response of the material can be thought of initially as being either cross-linking or degradation. Materials that cross-link in radiation become stiffer and less pliable and those that degrade can decompose to a form that has no mechanical strength, such as a powder or a liquid. Experience at SRS shows that given sufficient time, PTFE exposed to tritium in air decomposes and forms HF. HF combines with water vapor in the air to form hydrofluoric acid, which in turn corrodes any stainless steel that is in contact with PTFE.

There is a large amount of data regarding the exposure of polymers to gamma irradiation in air, which is directly applicable to using polymers in nuclear power reactors (pumps, valves, etc.). Using polymers in a tritium system is a specialized area, with little or no scientific data extant. To choose polymers for tritium service, it is generally assumed that those polymers relatively more resistant to gamma radiation in air (for which data exist) are a better choice than those less resistant. Several factors differentiate exposure to gamma irradiation in air from tritium exposure. The energy of tritium beta particles $(5.7 \mathrm{keV}$ average, $18.6 \mathrm{keV}$ maximum) is very low compared to that typical for gamma irradiation in nuclear environments. Normally the penetration depth of low energy beta radiation is quite small, however tritium can cause radiation damage throughout the bulk because it completely permeates polymers. In fact, tritium can isotopically exchange with protium atoms that comprise the polymer, actually becoming part of the polymer. Oxygen has been shown to be an important factor that accelerates radiation damage of polymers [2], and in tritium systems there is little or no oxygen. For these reasons, using the published relative stability of polymers irradiated with gamma rays in air may indicate relative stability but cannot predict detailed behavior or predict lifetime in oxygen-free tritium exposure. Thus there is the need for basic data on polymer aging in tritium that this program will address. This memorandum describes experimental results of exposure of the first set of UHMW-PE, PTFE, and Vespel® samples to one atmosphere tritium for 108 days. Longer exposures will be studied using the same techniques in the future.

\section{SAMPLE EXPOSURE TO TRITIUM}

Sheets of UHMW-PE, PTFE, and Vespelß were procured from Professional Plastics (Austin, TX 78758). All sheets were nominally 0.062 " thick. The PTFE was "virgin" TFE, and the Vespel ${ }^{\circ}$ grade was SP-1 (without fillers). Fourier transform infrared spectroscopy (FT-IR) of the as-procured sheets (performed by the Analytical Development Section of SRTC) verified that the supplier sent the desired material in all three cases. The sheets were stored in drawers, away from direct fluorescent lighting, to avoid the expected radiation damage by ultraviolet light. Rectangular samples were cut to nominally $3 / 8$ " by $11 / 4$ ". Four such samples of each polymer were chosen for the 108-day exposure described in this report. One of these pieces was cut again prior to exposure to form two pieces nominally $3 / 8$ " by 0.42 " ("small" sample) and $3 / 8$ " by 0.83 " " "medium" sample). Of the total of five samples of each polymer, the three $3 / 8$ " by $1 \mathrm{l} / 4$ " samples are designed for testing by Dynamic Mechanical Analysis (DMA) and the small and medium samples were sized differently to allow the volume and mass of each to be measured before and after exposure. All five samples of each polymer were inserted in a stainless steel tubular exposure cell having double valves and qualified for tritium service. Only one type of polymer was inserted in each cell.

The three exposure cells were evacuated overnight in the Experimental Tritium Manifold in the Materials Test Facility, Building 232-H, achieving less than 1 micron per minute rate of rise (over 10 minutes). The cells were then pressurized to nominally 760 torr tritium gas, sealed, and removed from the manifold. All three exposure cells contained tritium for 108 days. The exposure temperature was the ambient temperature of the hood where the exposure took place, usually about 25 degrees $\mathrm{C}$. After exposure, each cell was remounted on a calibrated minimal volume portion of the manifold, and the total pressure in each cell was measured after exposure. (Prior to the tritium exposure, the empty cell volumes were measured, and the volume of the polymer samples in each cell was calculated knowing the mass and density of the polymers.) After the total pressure measurement, the remaining gas was expanded into a gas sample bottle for mass spectroscopy. The exposure cells were then evacuated overnight, until no offgassing was detectable by a ten- 
minute rate of rise test. The cells were then removed from the manifold and stored until each was opened for testing. Because of the known significant effects of oxygen on radiation damage of polymers, each exposure cell remained evacuated until just before experimental characterization could occur for each polymer type. The UHMW-PE cell remained evacuated for 15 days, the PTFE cell for 21 days, and the Vespel® cell for 35 days. Each cell was opened by slowly opening the top fitting, while minimizing the hood ion chamber ("Kanne") alarm. Immediately after the cell was completely opened, the $3 / 8$ " by 0.42 " and $3 / 8$ " by 0.83 "samples were weighed and their dimensions measured with an electronic caliper. The three $3 / 8$ " by 1 $1 / 4$ " DMA samples were then placed in a plastic container with holes in the top. The plastic containers were then transferred to the hood for DMA and colorimetry testing. Radiological Protection Division personnel supervised these transfers. The $3 / 8$ " by 0.42 " and $3 / 8$ " by 0.83 "samples remained in the Experimental Tritium Manifold hood for FT-IR spectroscopy. The time in air was minimized as much as practical to avoid oxygen dissolving in the samples and affecting properties of the tritium-containing polymer samples.

\section{EXPERIMENTAL METHODS AND RESULTS}

\section{Density}

The mass and volume of the small and medium samples for all three polymers were measured before and after exposure. The mass was measured on balances capable of measuring to $t /-0.001$ gram. The volume was found by measuring the length, width, and thickness of the small and medium samples using an electronic caliper (to a precision of $0.01 \mathrm{~mm}$ ), and the volume was calculated assuming the samples were rectangular. The mass and volume of exposed samples were measured in the Experimental Tritium Manifold hood immediately after they were removed from the exposure cell.

The density was calculated by dividing the mass in grams by the volume in cubic centimeters. The density of UHMW-PE and Vespel $B$ increased after 108 days exposure by $2.3 \%$ and $4.4 \%$ respectively, and that of PTFE decreased by about $2.7 \%$ (Fig. 1). These percentage changes are averages of the two density changes measured for each polymer, and differences between values found for a given condition reflect the accuracy of the measurements. The change in volume of all the polymers was greater than the change of mass, and the volume change accounted for the change of density. That is, the UHMW-PE and Vespelß shrunk and the PTFE grew.

\section{Visual Appearance}

Visual inspection of the samples after exposure revealed that the UHMW-PE changed dramatically, from the normal milky white to purple. The PTFE grayed slightly from the normal bright white, and the color of the originally brown Vespel@ remained the same after tritium exposure.

\section{Colorimetry}

A spectracolorimeter (Photo Research model PR-650, Chatsworth CA) was used to measure the color of unexposed samples and DMA samples exposed to tritium for 108 days. A 300-watt xenon light was used to illuminate the flat samples at a 45-degree angle and the colorimeter was aimed normal to the surface of the sample being measured. This arrangement eliminates specular reflection. The correlated color temperature (CCT) of a reflectivity standard illuminated by the lamp was measured to be about $4936 \mathrm{~K}$ as compared a CCT for sunlight of $4874 \mathrm{~K}$. The output of the colorimeter is two numbers that describe the color, termed " $x$ " and " $y$ ". These $x$ and $y$ values are coordinates on what is known as the 1931 CIE chromaticity diagram and represent the hue and saturation of the specimen. Any color can be specified as the $\mathrm{x}$ and $\mathrm{y}$ values along with the chromaticity diagram.

The change of these values was significant for UHMW-PE and PTFE, and was not significant for Vespel@ (Figs. 2, 3). One unexpected result was that although the UHMW-PE appeared to the eye to have darkened considerably more than the PTFE (above), the measured colorimeter changes were about the same (Fig. 2). 


\section{Dynamic Mechanical Analysis}

\section{Description}

Dynamic mechanical analyzers are devices that measure the modulus of materials. The modulus is the constant that relates the strain (or change of length per unit length) to the stress (applied force per unit area). Polymers have an instantaneous and a time dependent response to applied forces, and the modulus of polymers is represented by a complex number. The real part of the modulus, called the storage modulus, expresses the amount of stored elastic energy in the material when under load. (Stored elastic energy is recoverable when the load is released, as in a spring.) The imaginary part of the modulus, called the loss modulus, represents the time-dependant deformation, or visco-elastic deformation that occurs as a function of time after the initial load is applied. The loss modulus is a measure of how much energy is dissipated as heat in response to the applied load, and this energy is not recoverable. Changes in the polymer molecular structure, such as the glass transition or melting, are reflected in both the storage and loss moduli. Using the modulus to characterize effects of tritium on polymers both directly monitors the mechanical properties of the polymer and potentially provides a means to infer molecular structure changes.

Two identical DMAs were procured, Model 2980 made by TA Instruments (New Castle, DE). One was altered by the manufacturer to reduce the size of equipment placed in an air hood in Building 232-H. This DMA was used for all tests of tritiated samples. The other DMA was used for testing unexposed samples (located in Building 773-A). Many types of tests and sample configurations are available, and the sample configuration chosen for this work was the three-point bend configuration. This configuration was chosen in part to simplify handling in the hood, which is a Contamination Area. All DMA tests used a continuous temperature ramp of $1^{\circ} \mathrm{C}$. per minute, starting at $-60^{\circ} \mathrm{C}$. The DMA measured the storage modulus, loss modulus, and the quantity tan delta. Tan delta is related to the storage and loss moduli by

Tan delta $=$ Loss modulus/storage modulus

The DMA measured the three quantities continuously as the temperature increased. Four frequencies were chosen for study: $1,3,10$ and $30 \mathrm{~Hz}$ based on preliminary tests. $30 \mathrm{~Hz}$ was the maximum frequency at which the DMA remained stable over the entire temperature range studied for each polymer, and $1 \mathrm{~Hz}$ is a common DMA test frequency. Employing several test frequencies potentially reveals additional information about thermally activated processes, such as molecular motion.

\section{Results: UHMW-PE}

108 days of exposure to 1 atmosphere tritium resulted in an increase of the storage modulus for UHMW-PE at all temperatures (Fig. 4a). The storage modulus increased slightly with frequency for both the unexposed and 108 day samples. The loss modulus for unexposed UHMW-PE has a broad peak, whose temperature depends on frequency (Fig. 4b). This behavior was similar to the loss modulus observed for the 108 day tritium exposed sample, except that the peaks for each applied frequency occurred at lower temperature. The magnitude of the loss modulus was lower for the exposed material than the same value for the unexposed material. The frequency dependence of the loss modulus inverted the order at about $20^{\circ} \mathrm{C}$. and the unexposed and 108 day exposed UHMW-PE behaved similarly. The tan delta shows a marked change due to 108 days exposure (Fig. 4c). The unexposed tan delta increases significantly at elevated temperatures (at different temperatures depending on frequency), however the exposed sample had significantly less of an increase. The change of all three UHMW-PE moduli by 108 days exposure is consistent with radiation induced crosslinking, resulting in a "stiffening" the polymer and reducing molecular motion especially at elevated temperatures. 
The storage modulus of PTFE increased considerably at all temperatures after 108 days exposure (Fig. 5a). Both exposed and unexposed PTFE has a marked decrease in the storage modulus between 25 and $35^{\circ} \mathrm{C}$., and the increase of the storage modulus due to exposure was about the same proportion below and above this temperature range. The storage modulus increased with frequency for both unexposed and exposed samples, at all temperatures. The loss modulus shows a pronounced peak at about $28^{\circ} \mathrm{C}$., independent of frequency and exposure (Fig. 5b). The loss modulus appears greater for the exposed material below this peak, and becomes about the same above the peak. At very low temperatures, lower applied frequencies have a lower loss modulus, however this relation reverses (lower frequencies have a higher modulus) at $-18^{\circ} \mathrm{C}$. until the peak at $28^{\circ} \mathrm{C}$. After the peak, the lower frequencies return to lower values of loss modulus. All of the changes of frequency dependence of the loss modulus are the same for exposed and unexposed samples. The results of tan delta for PTFE are similar to the loss modulus (Fig. 5c), however a second peak appears at about $133^{\circ} \mathrm{C}$. for both exposed and unexposed, and the tan delta for exposed PTFE is less than that of unexposed material. Overall, PTFE appears to be crosslinking and stiffening, however the increase in loss modulus reveals an increase in energy dissipation, rather than the expected decrease (as observed in UHMW$\mathrm{PE}$ ) if only crosslinking was occurring. This result suggests that other changes are occurring in addition to crosslinking.

\section{Results: Vespel@}

The effects of 108 days tritium exposure on Vespelß were significantly less than the other two polymers studied. The storage modulus increased marginally over the entire temperature range studied (Fig. 6a). The dependence of storage modulus on frequency was small and the same for exposed and unexposed material. The loss modulus for exposed Vespel $®$ was less than unexposed below $0^{\circ} \mathrm{C}$. and above $70^{\circ} \mathrm{C}$. and about the same between these two temperatures (Fig. 6b). The behavjor of tan delta was similar to the loss modulus (Fig. 6c).

\section{Results: Samples at longer times in air}

The results described above (Figs. 4, 5, 6) are for the first sample of each polymer, exposed to air for about one day after being removed from the evacuated exposure cell. Replicate samples of each were tested two days and about one week after exposure to air resulted in similar behavior for all three materials. Oxygen is expected to play a role in radiation damage as discussed above, however, the time of exposure to air, up to about one week, appears to be insufficient for significant oxygen effects to be observed.

\section{Infrared Spectrometry}

Infrared spectra potentially provide two types of information: the amount of tritium incorporated in the sample and details of the chemical bond changes in the polymer. When infrared radiation impinges on a sample, radiation may be absorbed if the wavelength corresponds to the energy of a thermal vibration of a specific bond. Infrared spectra are presented as the percent transmittance as a function of the wavenumber (inverse wavelength).

Fourier transform infrared (FT-IR) spectrometry was conducted on the solid polymer samples by means of the attenuated total reflectance technique (ATR) with a Bruker Vector 22 FT-IR instrument equipped with a Pike MiRacle ATR attachment, using a ZnSe ATR crystal. This instrument has the advantage of being small enough to fit in the Experimental Tritium Manifold hood. The ATR FT-IR technique is a nondestructive method for examining solid samples. The polymer sample is clamped in the ATR apparatus, which presses it onto the ATR crystal surface. Infrared light impinges on the crystal and probes the sample surface. The sampling depth is wavelength dependent but ranges between about 0.5 and $2.0 \mu \mathrm{m}$. All spectra were recorded at $2 \mathrm{~cm}^{-1}$ resolution. 
Important sample material properties that can affect the ATR measurement are index of refraction, opacity and modulus and surface roughness. If the sample's index of refraction is very similar to that of the detector crystal material, no 'total reflectance' occurs and no spectrum can be obtained. Likewise if the sample is too opaque at the infrared light's wavelength, total absorption occurs and no spectrum results. The sample modulus and surface roughness can play an important role in affecting the real contact area between the sample and crystal, enabling more or less surface area to be sampled. More surface area sampling produces more spectral peak intensity. Very stiff and rough materials do not conform as well to the ATR crystal surface. (Unless the material is as flat as the crystal, very stiff materials cannot be forced to have a large contact area with the crystal.)

Representative spectra are shown in Figures 7 through 12. Two aspects of sample behavior are indicated in the Figures, the exposure dependence of the spectra (Figs. 7, 9, and 11) and the heterogeneity of the samples (Figs. 8, 10,12). Figures 7 and 9 clearly show a loss of spectral intensity correlated to tritium exposure (UHMW-PE and PTFE respectively) that is not observed with the Vespel $($ samples (Fig. 11). Figures 8, 10 , and 12 show that there is significant spectrum-to-spectrum variation in spectral peak heights obtained at different locations on the sample. This will make interpreting peak heights more difficult. Preliminary scouting samples, not discussed earlier in this report, were exposed to $\sim 760$ torr tritium for periods of 48 days (PTFE), 52 days (UHMW-PE), and 112 days (Vespel®), and are included in the FT-IR analysis and the exposure gas analysis presented below.

The first main observation is the sample spectral intensity decrease observed with exposure in UHMW-PE (Fig. 7) and PTFE (Fig. 9). In both cases, the spectrum intensity degrades with exposure, and suggests that eventually no spectrum will be obtained if this trend continues. This could occur due to a change in the index of refraction of the sample. Spectra were collected using a Ge (germanium) ATR crystal, which has a different index of refraction than $\mathrm{ZnSe}$, to test this hypothesis. No significant spectral difference was observed in spectra obtained using ZnSe compared to Ge. Both modulus/surface roughness and opacity remain potential causes of spectral intensity decrease. This issue may lead to a decrease in utility of the ATR technique in more heavily exposed samples in the future.

The other principal observation is the observed loss of peak height coupled with the appearance of new and changed peaks (examples discussed below). Since each peak in an infrared spectrum is associated with a particular molecular vibration, peak reduction indicates that chemical moiety (functional group) is disappearing, while new peaks indicate the appearance of new moieties. Changes in peak shape are more difficult to interpret, but this also typically indicates a change in chemical structure. Peak broadening often indicates the appearance of chemical moieties that are similar but not identical to the original structures present in the sample.

In a simplified sense, UHMW-PE can be thought of as a bowl of spaghetti. In UHMW-PE the base chemical unit is a - $\mathrm{CH} 2$ - assembly, and these units are linked together to form long chains (noodles). The only other chemical moiety occurs at each end of a chain, where a single hydrogen atom bonds to terminate the chain. In UHMW-PE, the proportion of these - $\mathrm{CH} 3$ units is very small by design (enormous molecular weight).

Tritium-induced radiation damage has two aspects: i) chain scission / recombination and ii) isotope exchange. Chain scission involves the breaking of chemical bonds that then re-form differently. If protium or tritium caps off a broken bond, then a simple chain cleavage has occurred, reducing the molecular weight. If the broken bond attaches to another chain, cross-linking has occurred. This introduces chemical heterogeneity where none existed before, and the result is a broadening of the IR peak due to the new assemblies found at the newly formed chemical bonds. For example, the doublets at 1472 and $1459 \mathrm{~cm}^{-1}$ and 731 and $718 \mathrm{~cm}^{-1}$ in unexposed UHMW-PE are considerably changed by tritium exposure (Fig. 7). Note that radiation induced crosslinking of UHMW-PE is consistent with the DMA results (discussed above).

The other aspect of tritium induced radiation damage is the exchange of tritium for the hydrogen (or fluorine in PTFE) originally in the molecule. This exchange does not change the chemical structure as far as bonds 
go, but does alter the bond strengths and the masses that participate in the thermal vibrations that determine the wavenumbers and degree of infrared absorption spectra. The impact of tritium substitution is predicted to be shift of peaks to lower wavenumbers by a factor of the square root of the ratio of the masses. For tritium and protium this factor is 1.7. For example normal C-H stretches appear at about $3000 \mathrm{~cm}^{-1}$, and so C-T stretches are predicted to appear at about $1700 \mathrm{~cm}^{-1}$, which is what is observed (Fig. 7). In principle, the peak area of the new $\sim 1700 \mathrm{~cm}^{-1}$ peaks would be directly proportional to the polymer's tritium content, if there were no concomitant overall decrease in spectral intensity.

PTFE is a fully-fluorinated polyethylene. Ideally, no hydrogen exists in the polymer. However, tritium can still cause bond rearrangements and can still substitute into the chain in place of fluorine atoms. In this case there is a similar chemical structure to that found in UHMW-PE, namely a C-T bond, and the $\sim 1700 \mathrm{~cm}^{-1}$ peak is in fact observed with a very similar peak shape as well (Fig. 9). As before, the tritium incorporation might be quantifiable, but this has been complicated by the spectral intensity changes. The peak shape changes of the $1202,1144 \mathrm{~cm}^{-1}$ doublet also indicates that chain cleavage and cross-linking is also occurring in PTFE.

Vespel® shows no significant spectral changes (Fig. 11), even though the gas analysis shows considerable protium-tritium exchange (Table I, discussed below). The Vespel spectra shown in Figure 11 are well within the range of spot-to-spot variation (Fig. 12). The relatively small peak shape changes indicates that very little cleavage and cross-linking is occurring, which was expected based on the structure of the Vespel $\otimes$ monomer unit (Fig. 13) having several aromatic rings that can absorb decay energy and so mitigate chain scission. Unfortunately no C-H stretches are observed in the Vespel $\otimes$ samples. These bonds do not seem to be "IR active", which means they do not absorb infrared radiation and so no C-H stretch peak will occur in infrared spectrometry. This result implies that tritium incorporation by Vespel® cannot be studied by infrared spectroscopy. However, since no chain scission and cross-linking seems to be present for these samples based on infrared spectroscopy (Fig. 11), material properties such as modulus will likely not change as dramatically with tritium exposure. This observation is consistent with the smaller effects observed by DMA on Vespelß discussed above.

Quantification of these spectral changes are made quite difficult by the change in overall sample absorbence with tritium exposure. An additional complicating factor is the spot-to-spot reproducibility of the spectra. As shown in Figures 8, 10, and 12 there is considerable variation observed, which makes quantitative interpretation difficult. More study of both these results and future samples having longer exposure to tritium may reveal more quantitative information.

\section{Mass Spectral and Total Pressure Analysis of Exposure Cell Contents}

After exposure to tritium, the exposure cells were mounted on the Experimental Tritium Manifold in a minimum volume configuration that included a pressure sensor and a gas sample bottle. After volume calibration by argon expansion, the exposure cell was opened to allow the tritium to expand into the small volume, and the pressure was recorded. Then the gas was expanded into a mass spectroscopy sample bottle and captured. The gas sample bottles for the scouting samples were removed and analyzed before evacuating the exposure cell. For the 108-day samples, the remaining gas was immediately evacuated from the exposure cell after the mass spectroscopy sample was taken. Sampling and evacuating the Vespelß scouting sample was delayed, however this fortuitously resulted in an approximately equal exposure time for the scouting and 108-day samples. Comparing results of these two Vespel@ samples should reveal the inherent variability of these experiments.

The pressure at the end of exposure in the unopened cells was calculated using the manifold and exposure cell volumetric calibrations (Table I below, Fig. 14). Both the Vespel $ß$ and PTFE show slight pressure drops from the original loading pressure of $\sim 760$ torr. However, the UHMW-PE shows a significant pressure increase, indicating a gas evolution reaction took place. Mass spectral analysis suggests the evolved gas is hydrogen. This increase was unexpected. 
Table I. Mass Spectroscopic Analysis and Total Pressure Results

\begin{tabular}{|c|c|c|c|}
\hline Material & $\begin{array}{c}\text { Aging Time } \\
\text { (Days) }\end{array}$ & $\begin{array}{c}\text { Total Pressure After } \\
\text { Exposure (torr) }\end{array}$ & \% Protium \\
\hline UHMW-PE & 52 & 830.8 & 32.21 \\
\hline UHMW-PE & 108 & 1292.3 & 63.03 \\
\hline PTFE & 48 & 642.3 & 1.68 \\
\hline PTFE & 108 & 639.4 & 23.98 \\
\hline Vespel@ & 108 & 686.5 & 49.54 \\
\hline Vespel@ & 112 & 629.1 & 47.86 \\
\hline
\end{tabular}

The gas samples were analyzed by high-resolution mass spectrometry, using the Analytical Laboratory in Building 234-H, and typical results include the various hydrogen isotope contents, and peak intensities for any significant species having mass of less than 50 AMU. Fragments attributable to substituted methanes were detected, but their peak intensities were very low, and they constituted less than $1 \%$ of the total gas. Polymer chain scission reactions from exposure to tritium are expected to produce simple hydrocarbon molecules. In longer tritium exposures, the methanes may increase to reliably measurable quantities.

Of primary interest is the appearance of significant protium isotopes in the tritium exposure gas. This indicates significant isotope exchange with the hydrogen content of the polymers. In principle, the PTFE sample has no protium available for exchange, being a totally fluorinated polymer, however hydrogen above the purity level of the load gas was detected (Table I). The $1.7 \%$ protium in the 48 -day sample is potentially attributable to dissolved water in the polymer, but a substantial amount of protium was detected in the 108day PTFE exposure cell. This result is very surprising and will be investigated further in the future.

The large protium content in the gas after exposure positively reveals that isotope exchange occurred between the polymer's protium and the dissolved tritium from the exposure gas (Table I). As discussed above, the excess pressure in the UHMW-PE exposure cells also indicates additional gas evolution above simple one-for-one exchange.

\section{SUMMARY and CONCLUSIONS}

UHMW-PE, PTFE, and Vespel® samples were exposed to $\sim 760$ torr tritium gas at ambient temperature for 108 days. Changes in properties of these materials were studied using dynamic mechanical analysis (DMA), Fourier Transform infrared spectrometry (FT-IR), visual observation, density measurements, and colorimetry. Changes of the exposure gas were characterized by total pressure measurements and mass spectroscopy.

1. Both DMA and FT-IR indicate that UHMW-PE exposed to tritium initially crosslinks and becomes stiffer. PTFE shows evidence of both crosslinking and chain scission, resulting in a stiffer material but additional molecular groups that dissipate mechanical energy and absorb infrared radiation. Vespelß shows little effect of tritium exposure in both DMA and FT-IR tests.

2. The density of UHMW-PE increased by about $2.3 \%$ and that of Vespel $\otimes$ increased $4.4 \%$, and the density of PTFE decreased by about $2.7 \%$.

3. The color of UHMW-PE changed from white to purple, that of PTFE changed from white to slightly gray, and the color of Vespel $\circledast$ was unchanged. Spectracolorimetry verified and quantified these visual observations. 
4. Analysis of the pressure and chemical composition of the exposure gas, along with FT-IR spectra, reveals that tritium isotopically exchanges with protium in the polymers. Protium is found in the exposure gas for all three polymers (unexpected for PTFE).

5. Low molecular weight carbon species were found in the gas after exposure, but at very low levels in all cases. There was an unanticipated net increase of exposure gas pressure for UHMW-PE, and a net decrease for PTFE and Vespelß. The main addition to the exposure gas was protium in all cases.

\section{REFERENCES}

1) D.C. Phillips. "Effects of radiation on polymers". Materials Science and Technology, Vol. 4, pp. 85-91 (January 1988).

2) K.T. Gillen, R.L. Clough. "A Kinetic Model for Predicting Oxidative Degradation Rates in Combined Radiation-Thermal Environments". J. of Polymer Science: Polymer Chemistry Edition, Vol. 23, pp. 2683-2707 (1985).

\section{ACKNOWLEDGEMENTS}

The authors thank David Bell and Mike Thomas for their support in setting up the tritium exposure and the DMA experiments, and especially Wanda Britt for her outstanding work (sample handling, DMA measurements, lab notebook maintenance, radioactive waste control). 

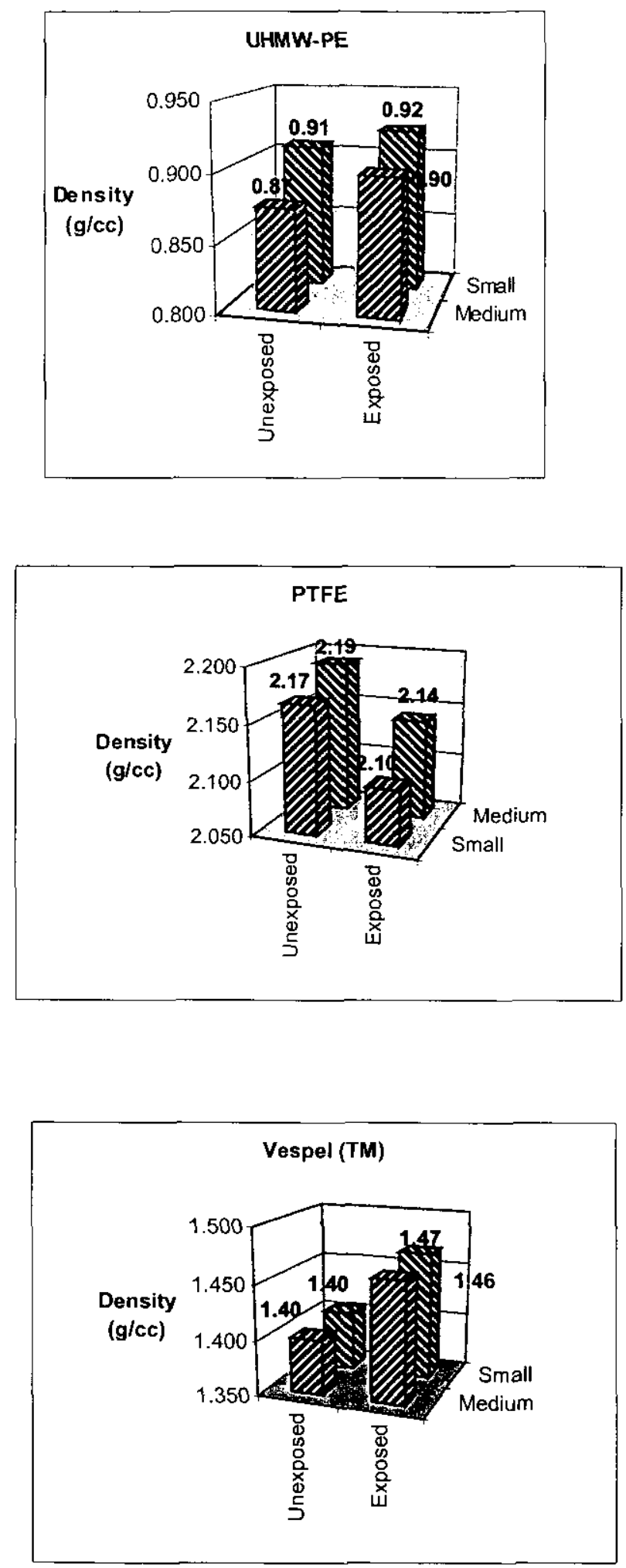

Figure 1. Density of UHMW-PE, PTFE, and Vespel® before and after exposure to 1 atm. Tritium gas for 108 days. Data from both small and medium samples plotted for each polymer. 


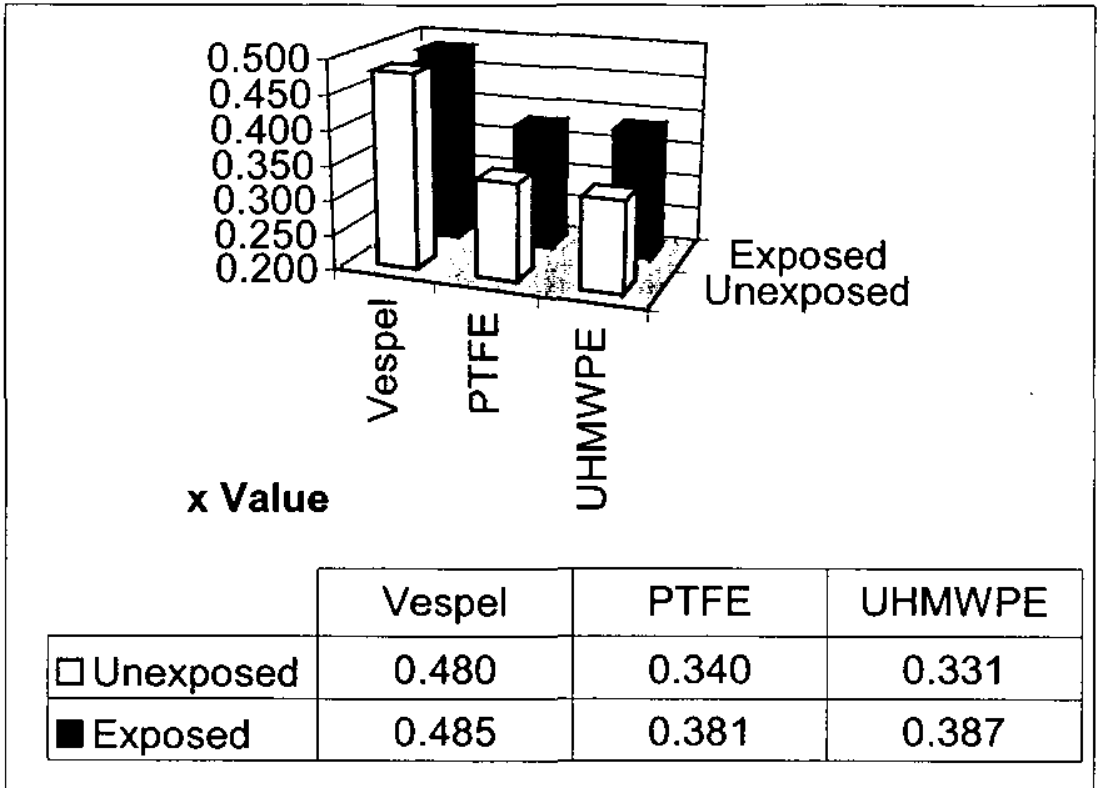

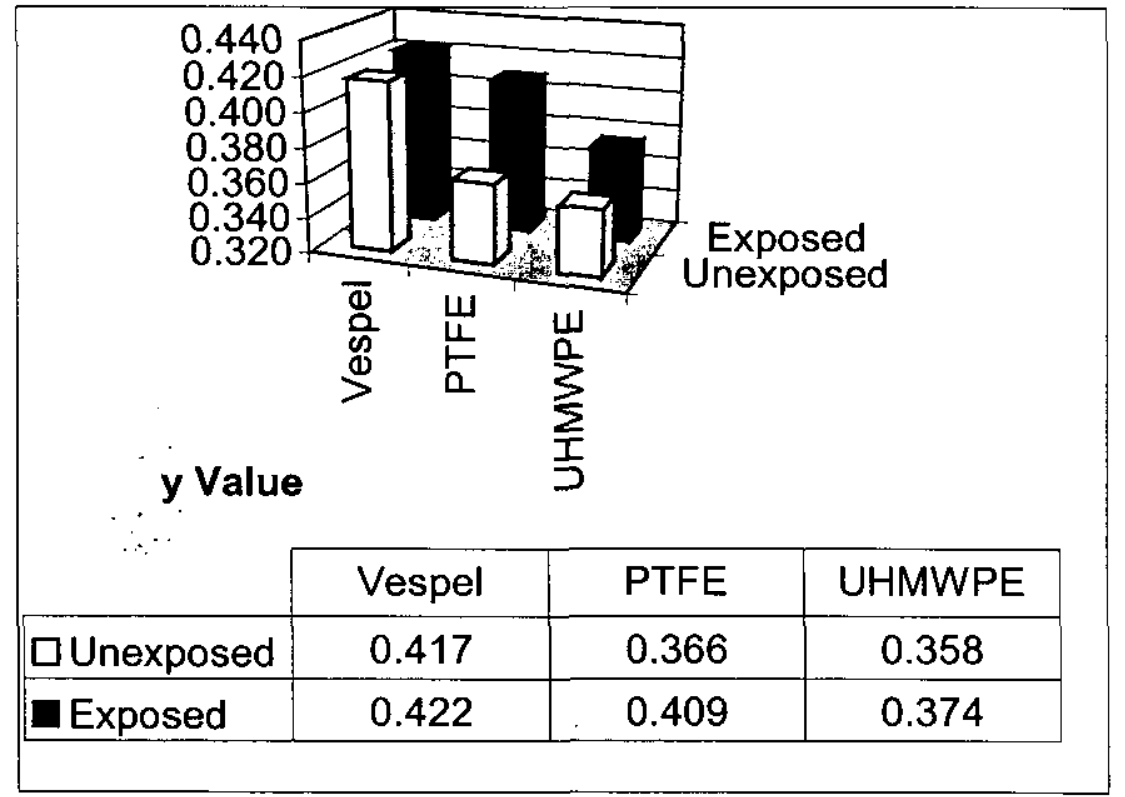

Figure 2. Colorimetry data for unexposed samples and samples exposed for 108 days to 1 atmosphere tritium. Note significant change in $\mathrm{x}$ value and $\mathrm{y}$ value for PTFE and UHMW-PE, compared to little change for Vespelß. 


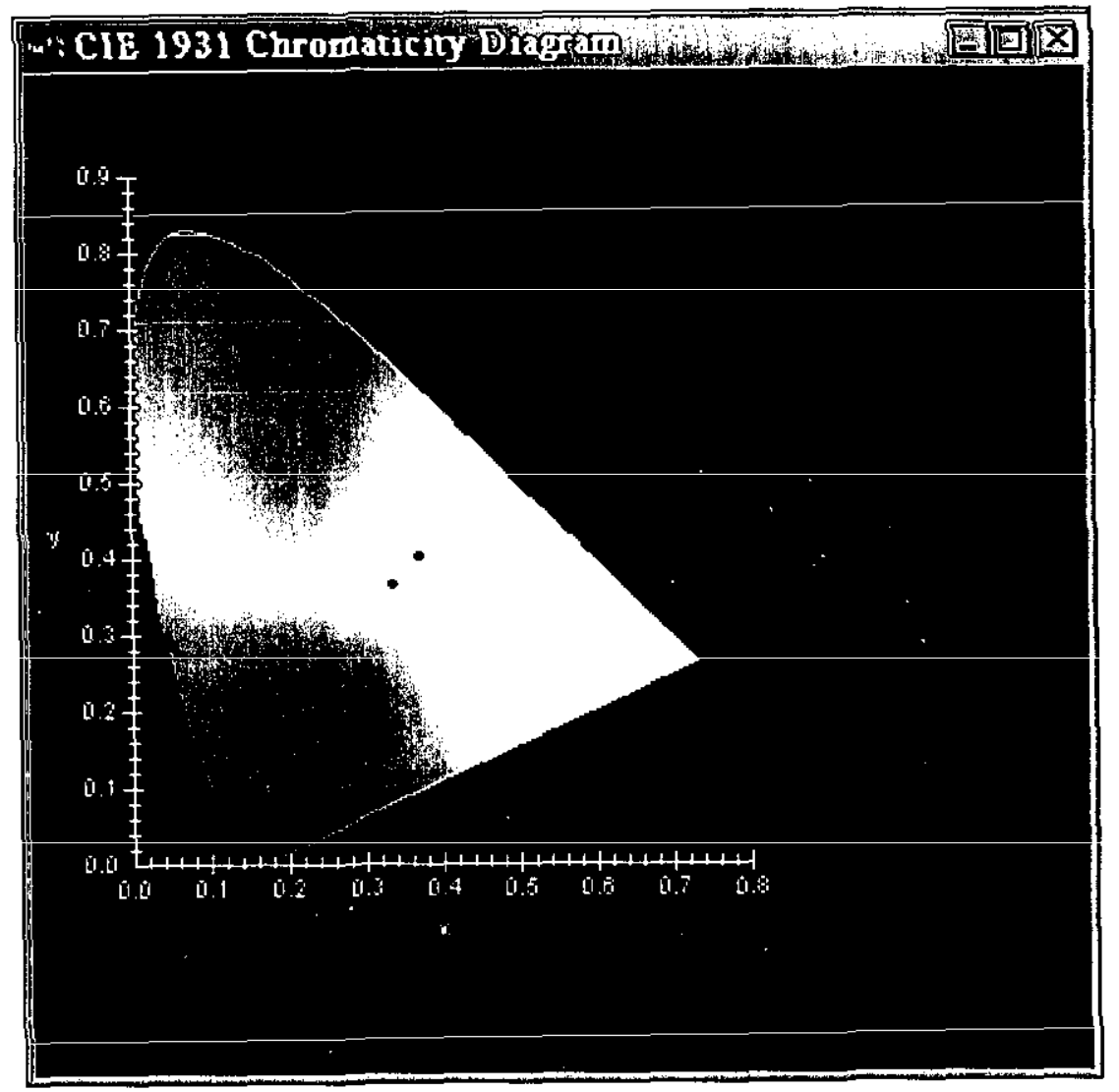

Figure 3. Chromaticity diagram for change of "x,y" value for PTFE. 1931 chromaticity diagram. Data from Fig. 2.

\section{BEST AVAILABLE COPY}




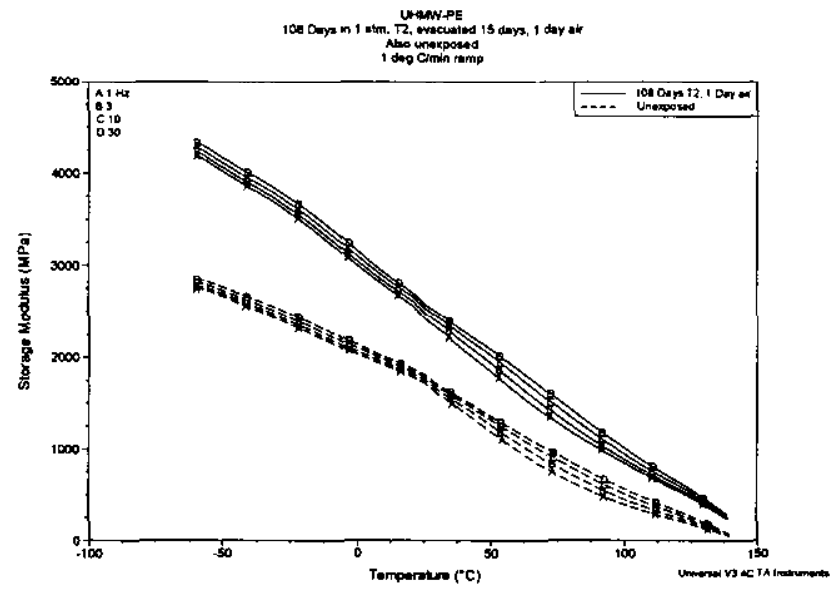

a.

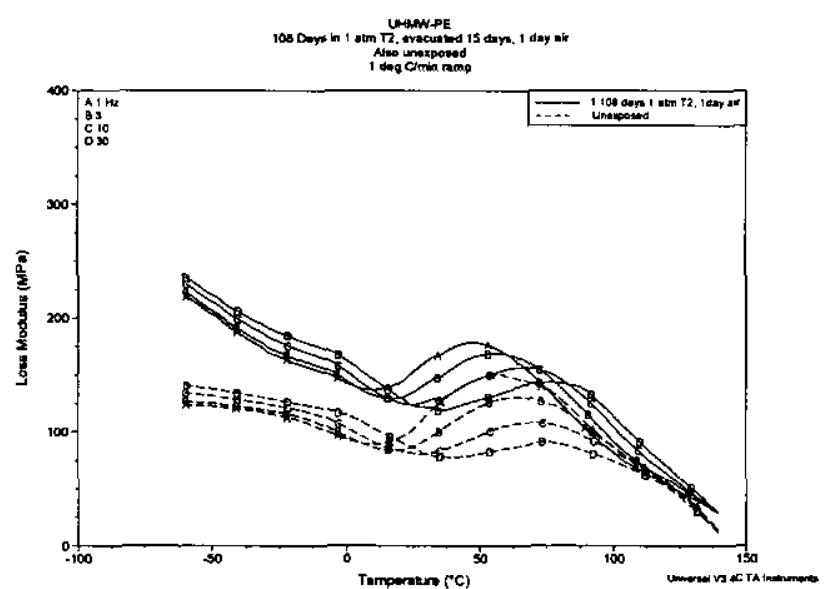

b.

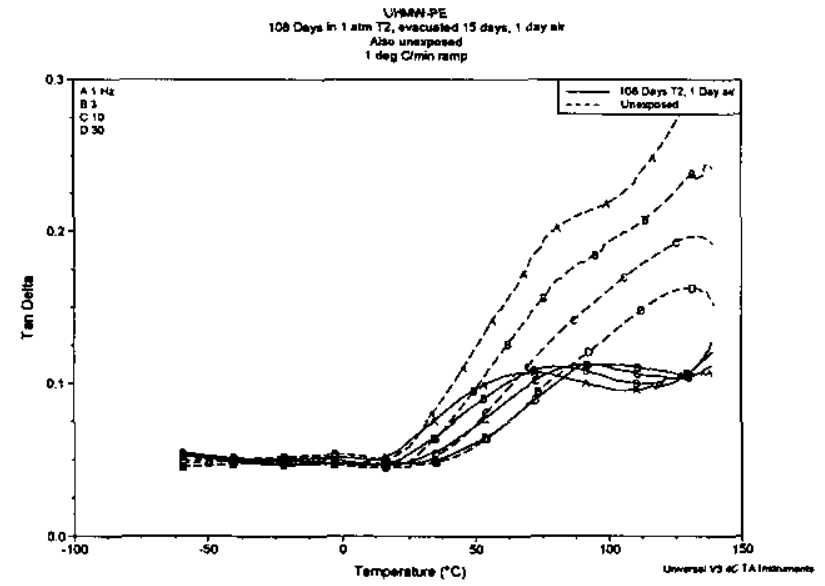

c.

Figure 4. Storage modulus (a.), loss modulus (b.), and tan delta (c.) for UHMW-PE sample exposed to 108 days of tritium at 1 atmosphere, and an unexposed sample. 1 degree $C$. per minute temperature ramp low to high. 


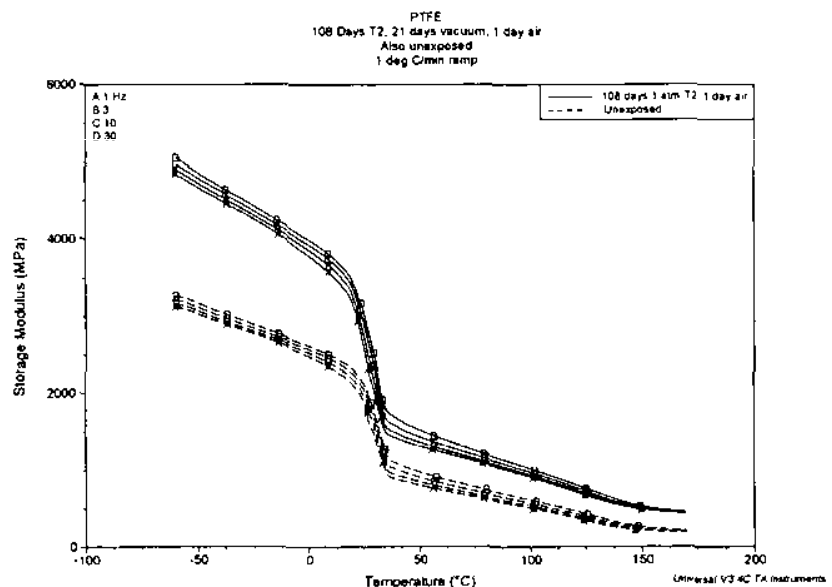

a.

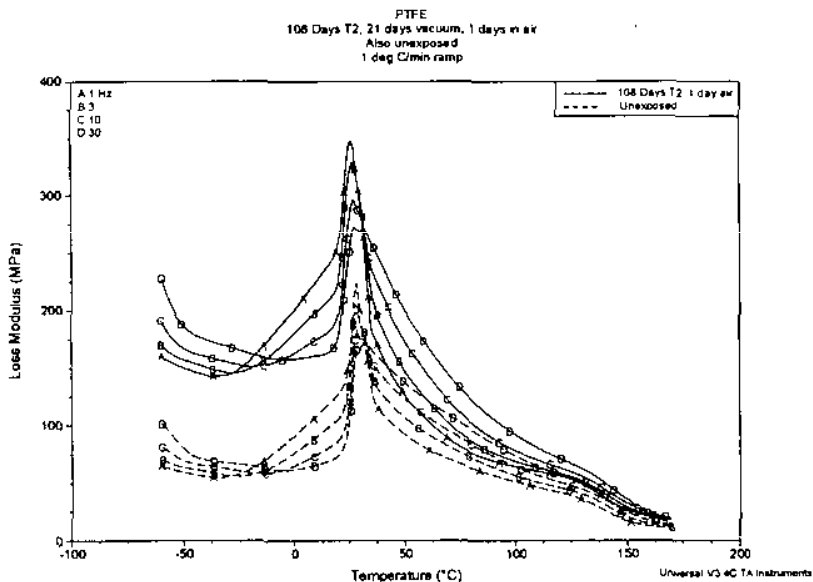

b.

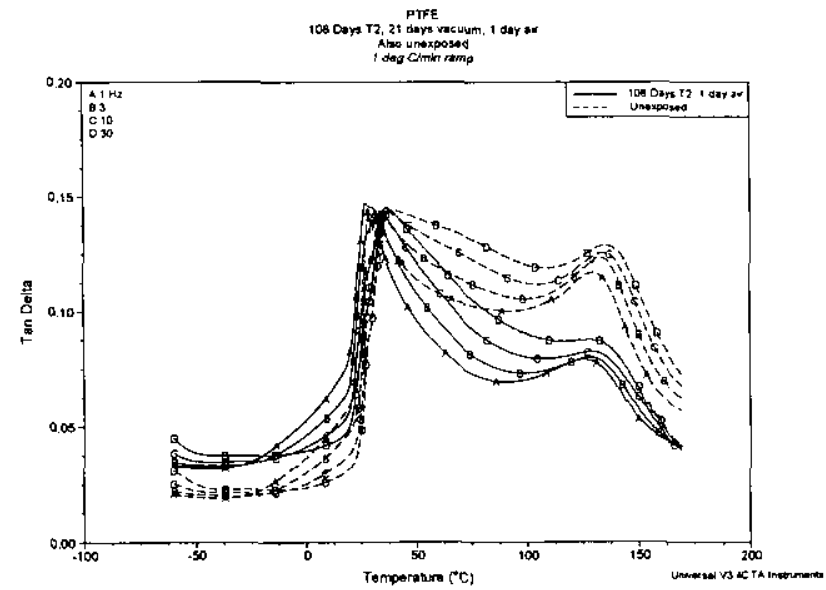

C.

Figure 5. Storage modulus (a.), loss modulus (b.), and tan delta (c.) as a function of temperature for PTFE sample exposed to 1 atmosphere tritium for 108 days, and an unexposed sample. 1 degree C. per minute temperature ramp low to high. 


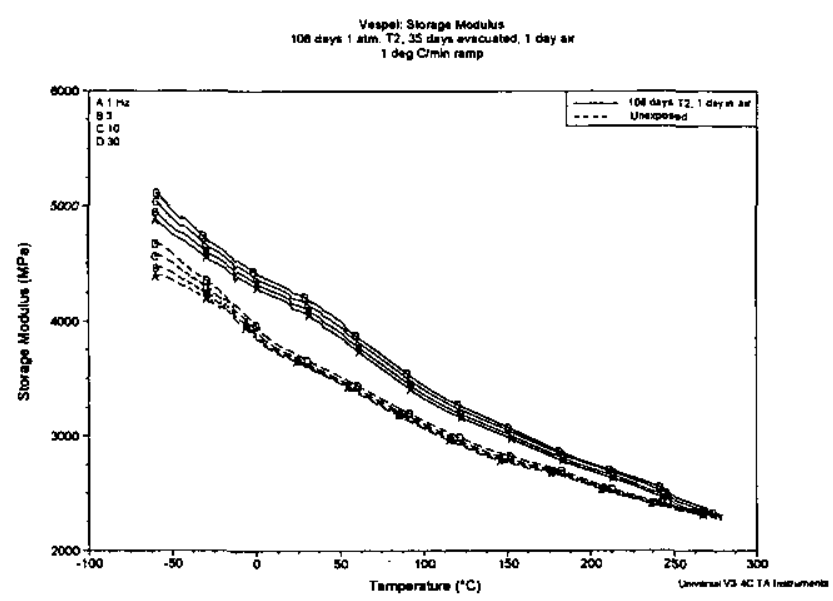

a.

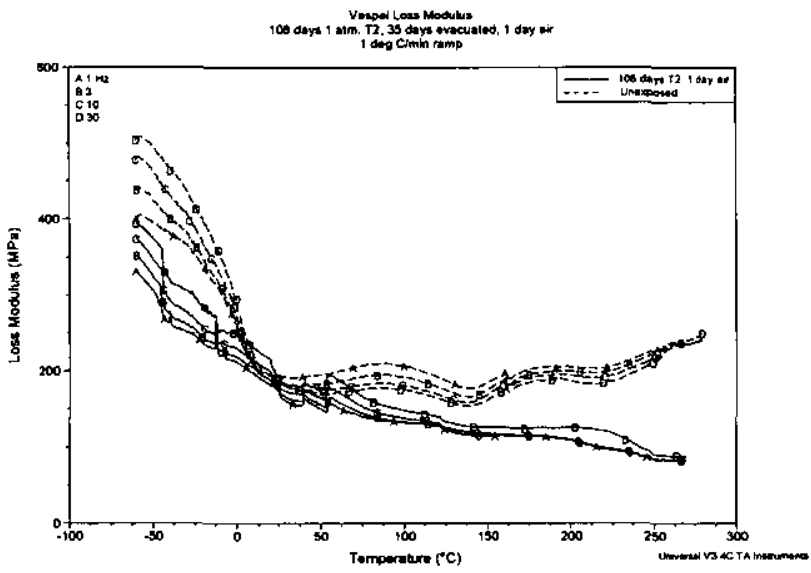

b.

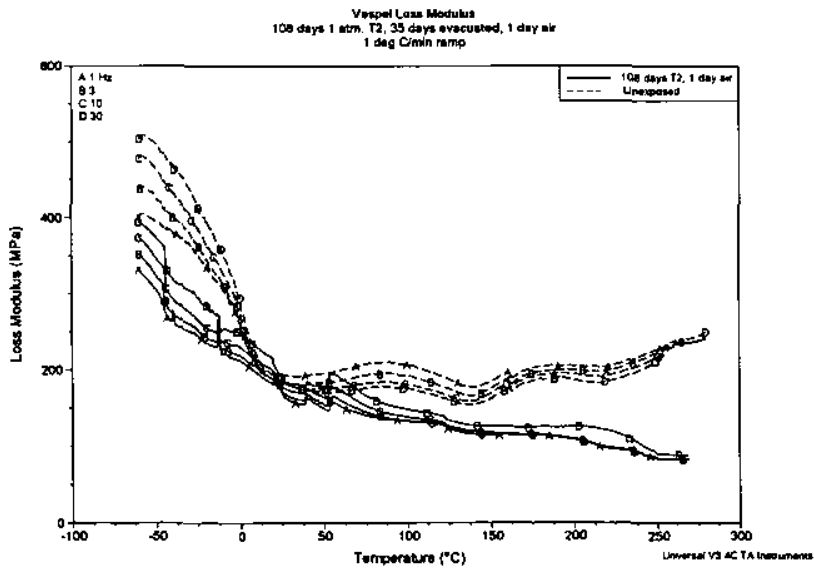

c.

Figure 6. Storage modulus (a.), loss modulus (b.), and tan delta (c.) as a function of temperature for Vespel $\otimes$ sample exposed to 1 atmosphere tritium for 108 days, and an unexposed sample. 1 degree C. per minute temperature ramp low to high. 


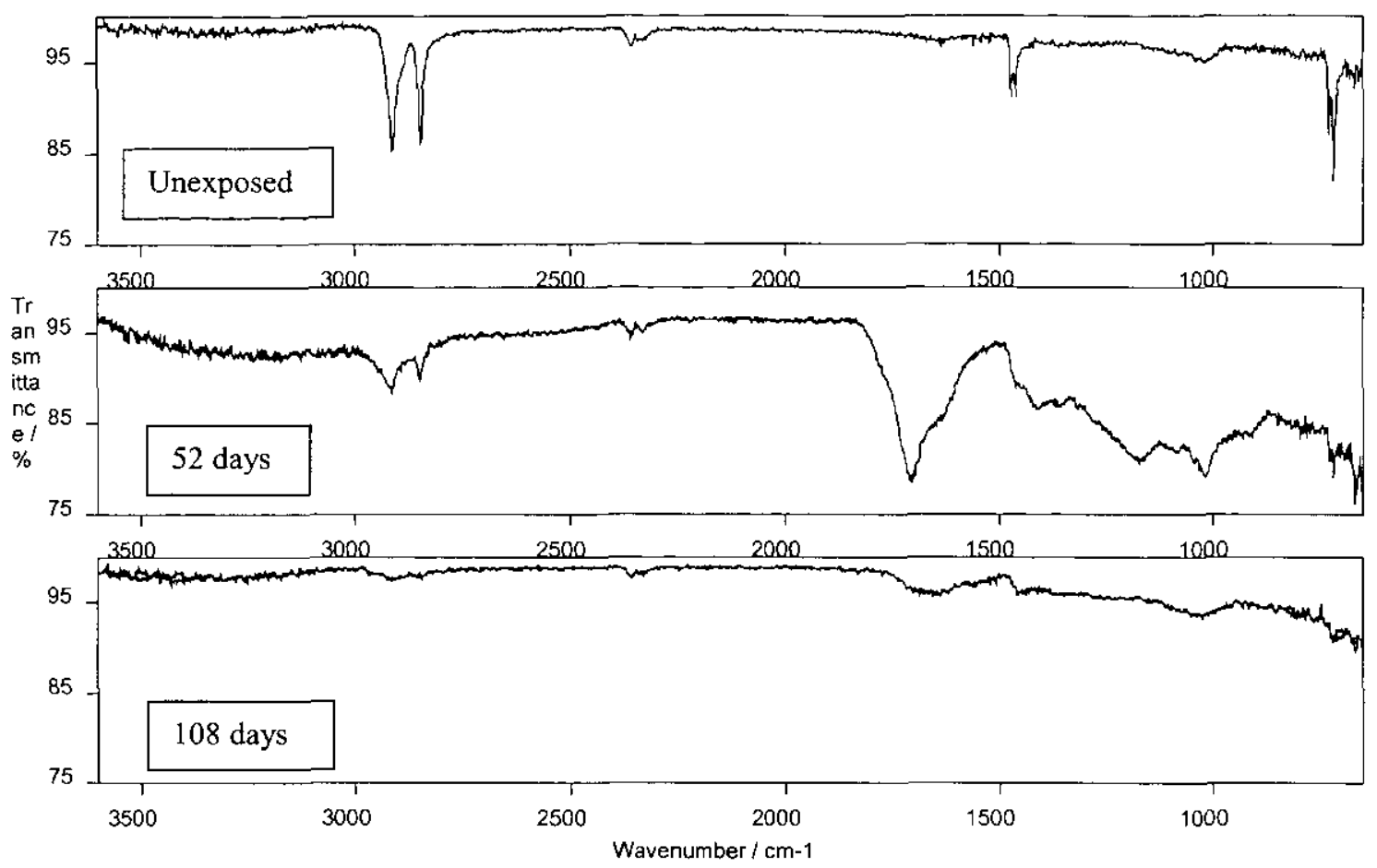

Figure 7. Representative ZnSe ATR FT-IR spectra (\% transmittance versus wavenumber) from unexposed and tritium exposed UHMW-PE. Exposure times indicated.

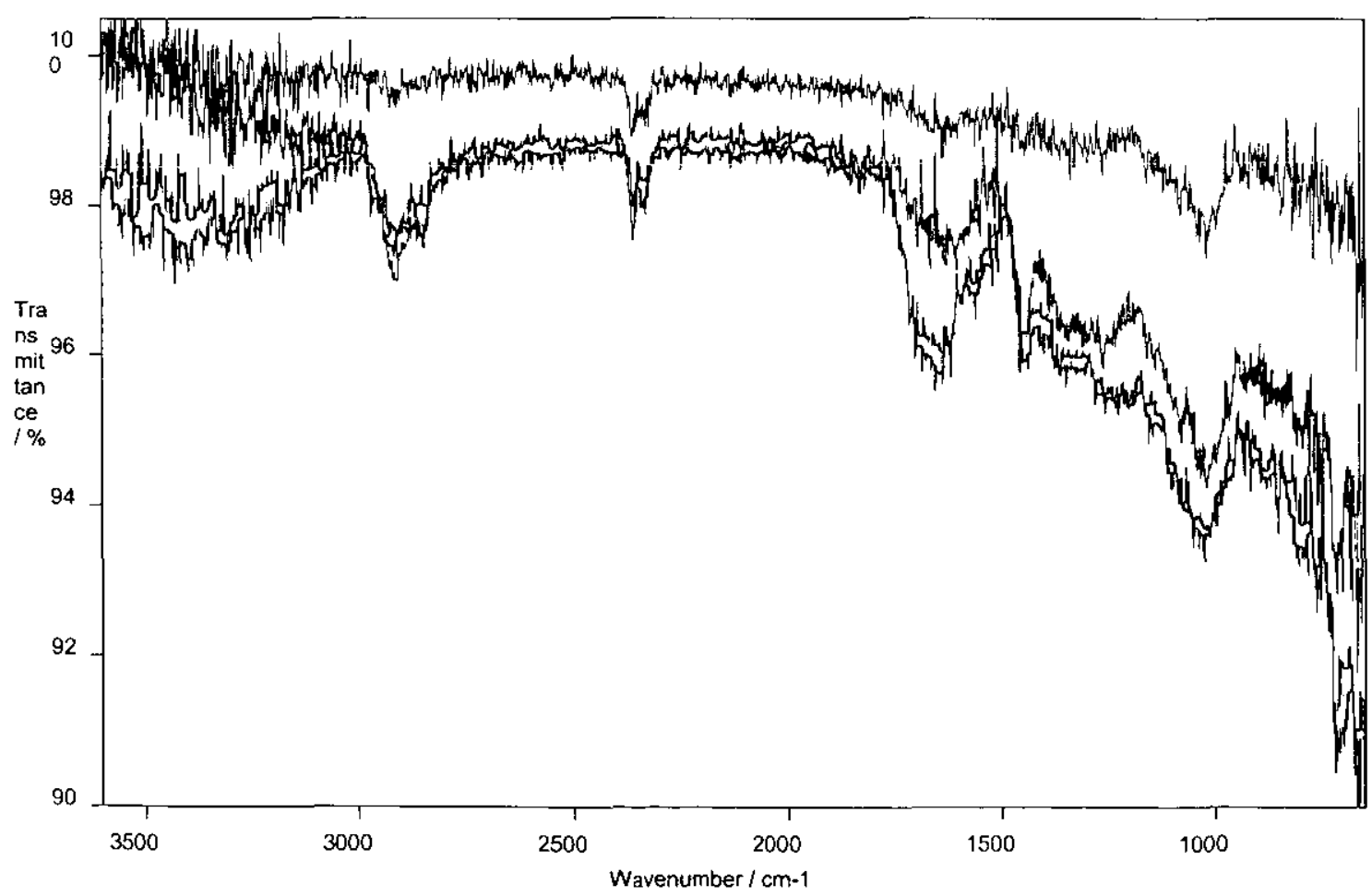

Figure 8. Representative spectra (\% transmittance versus wavenumber) from different locations on the same 108 day exposed UHMW-PE sample. 


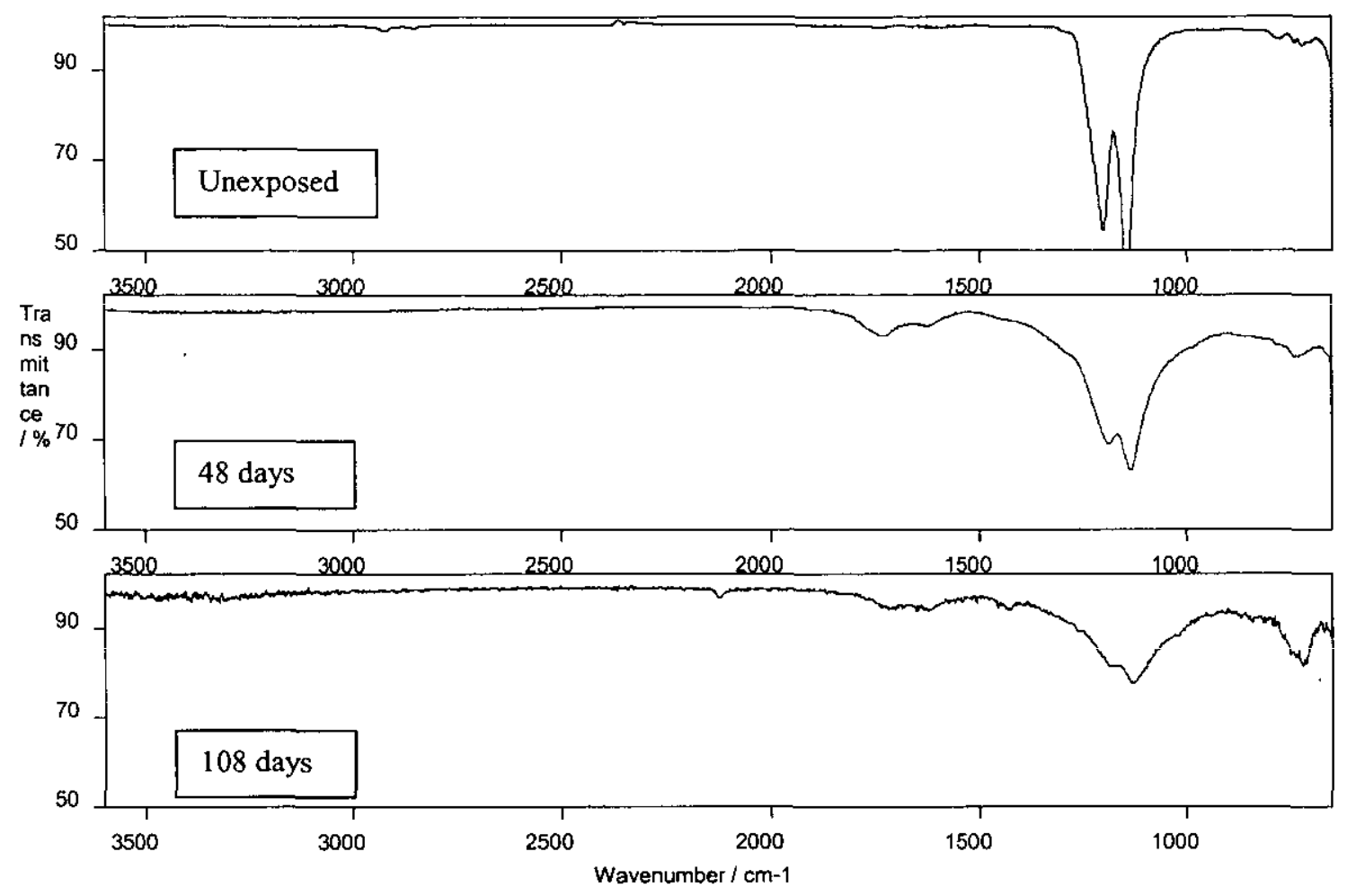

Figure 9. Representative spectra (\% transmittance versus wavenumber) from unexposed and tritium exposed PTFE samples. Exposure times indicated.

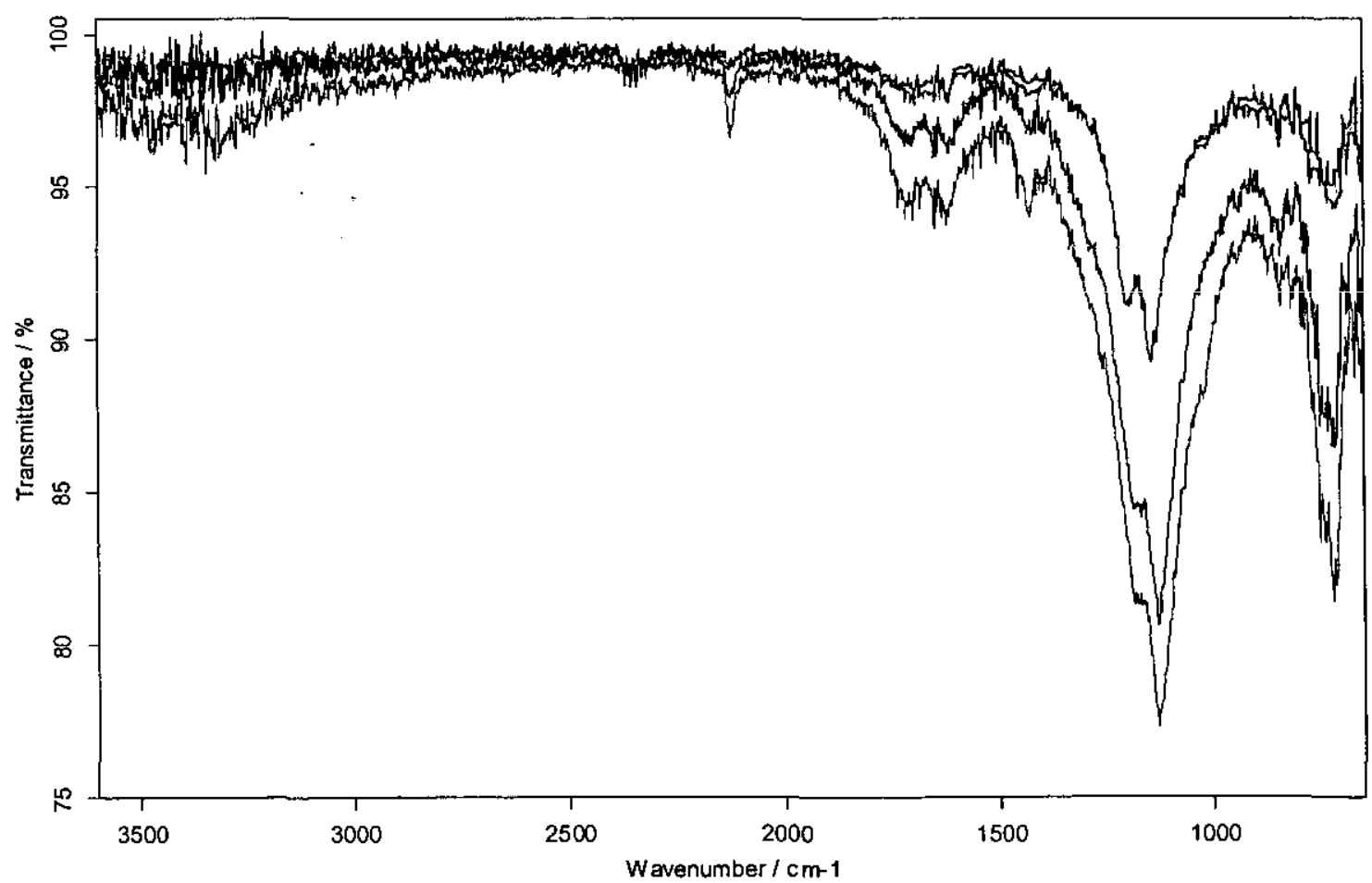

Figure 10. Representative spectra (\% transmittance versus wavenumber) from different locations on the same 108 day exposed PTFE sample. 


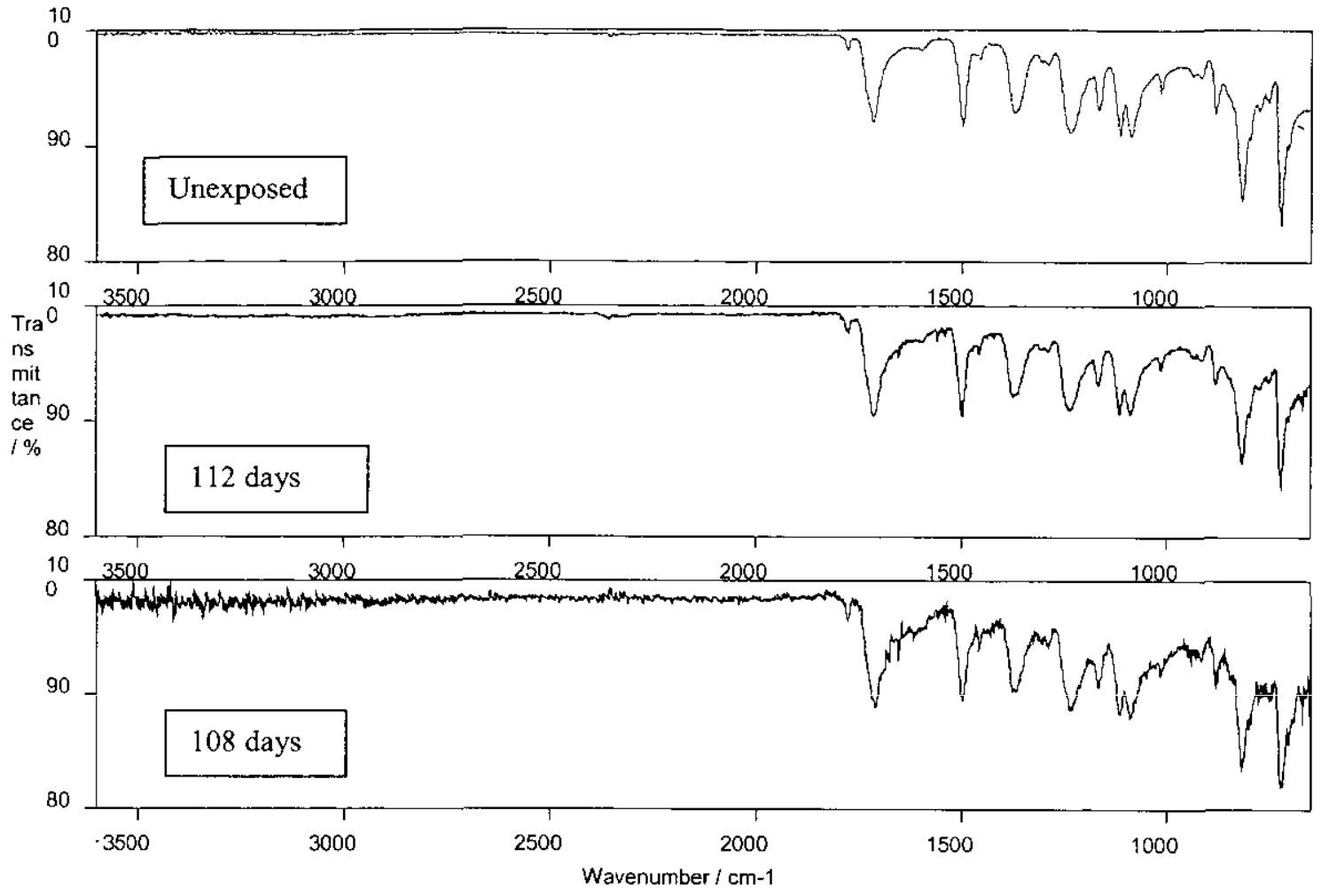

Figure 11. Representative ZnSe ATR FT-IR spectra (\% transmittance versus wavenumber) from unexposed and tritium exposed Vespel $($. Exposure times indicated.

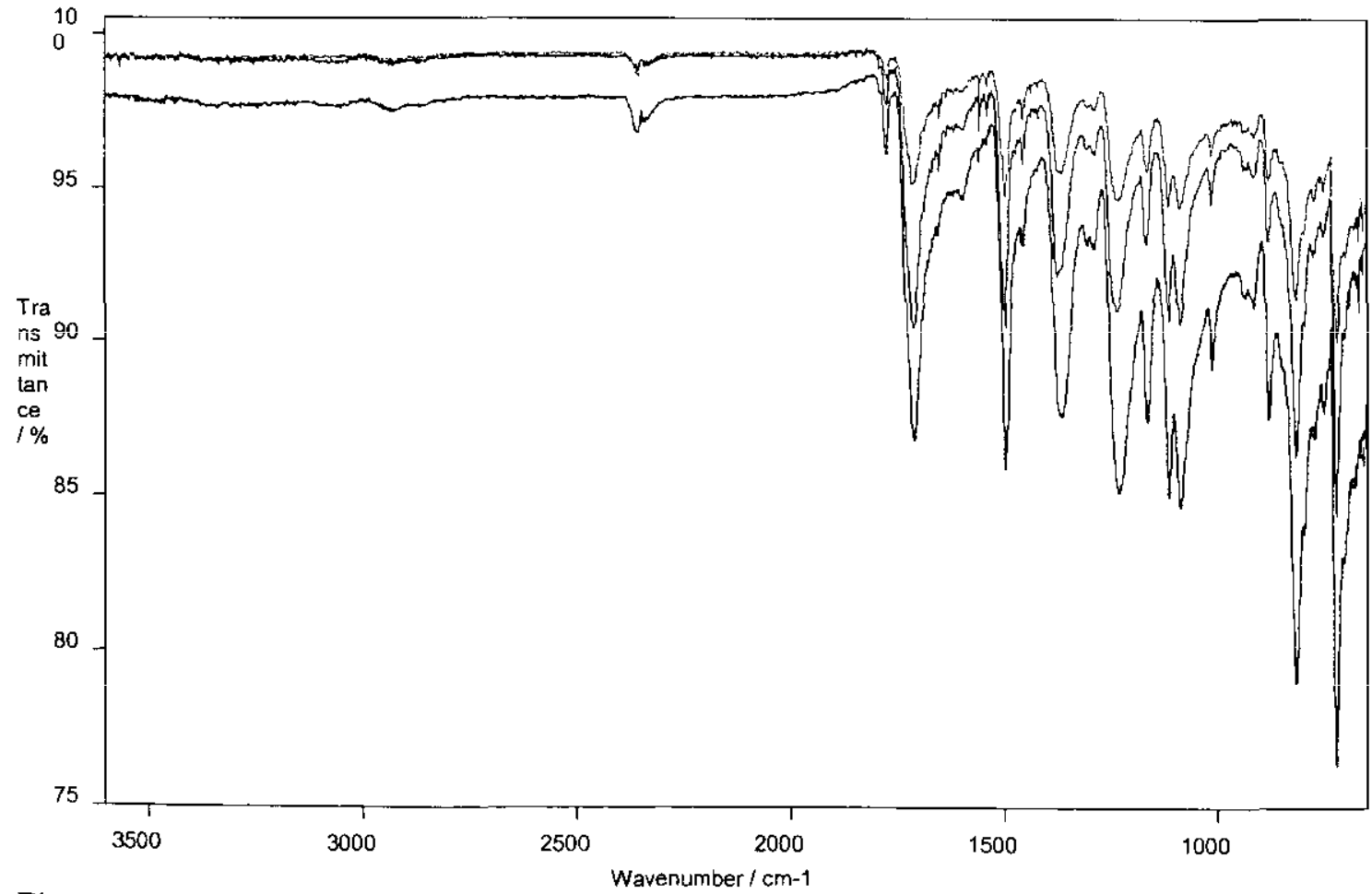

Figure 12. Representative spectra (\% transmittance versus wavenumber) from different locations on the same 108 day Vespel ${ }^{\circledR}$ sample. 


\section{Chemical formula of VeSPEt ${ }^{\text {B: }}$ SP}

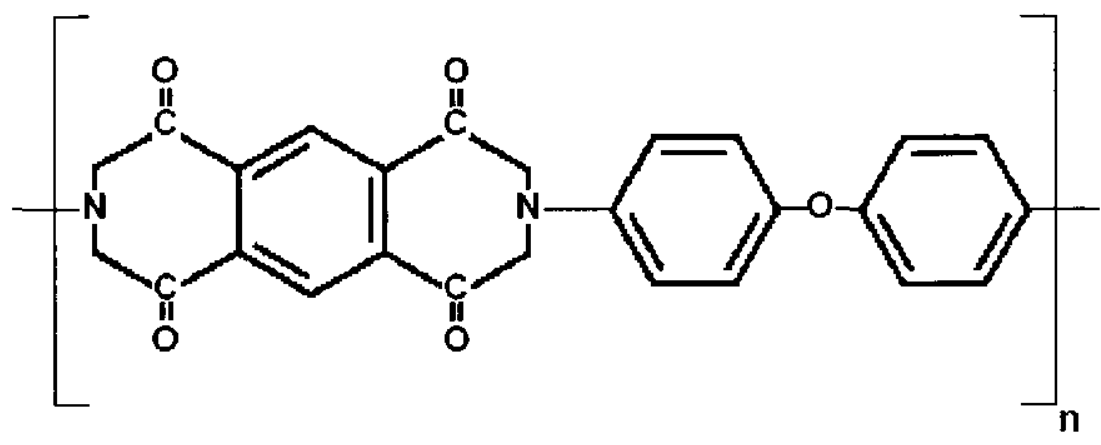

Figure 13. Vespel@ monomer unit chemical structure. 'SP' type of basic monomer structure, "SP-1" unfilled resin used for all experiments.

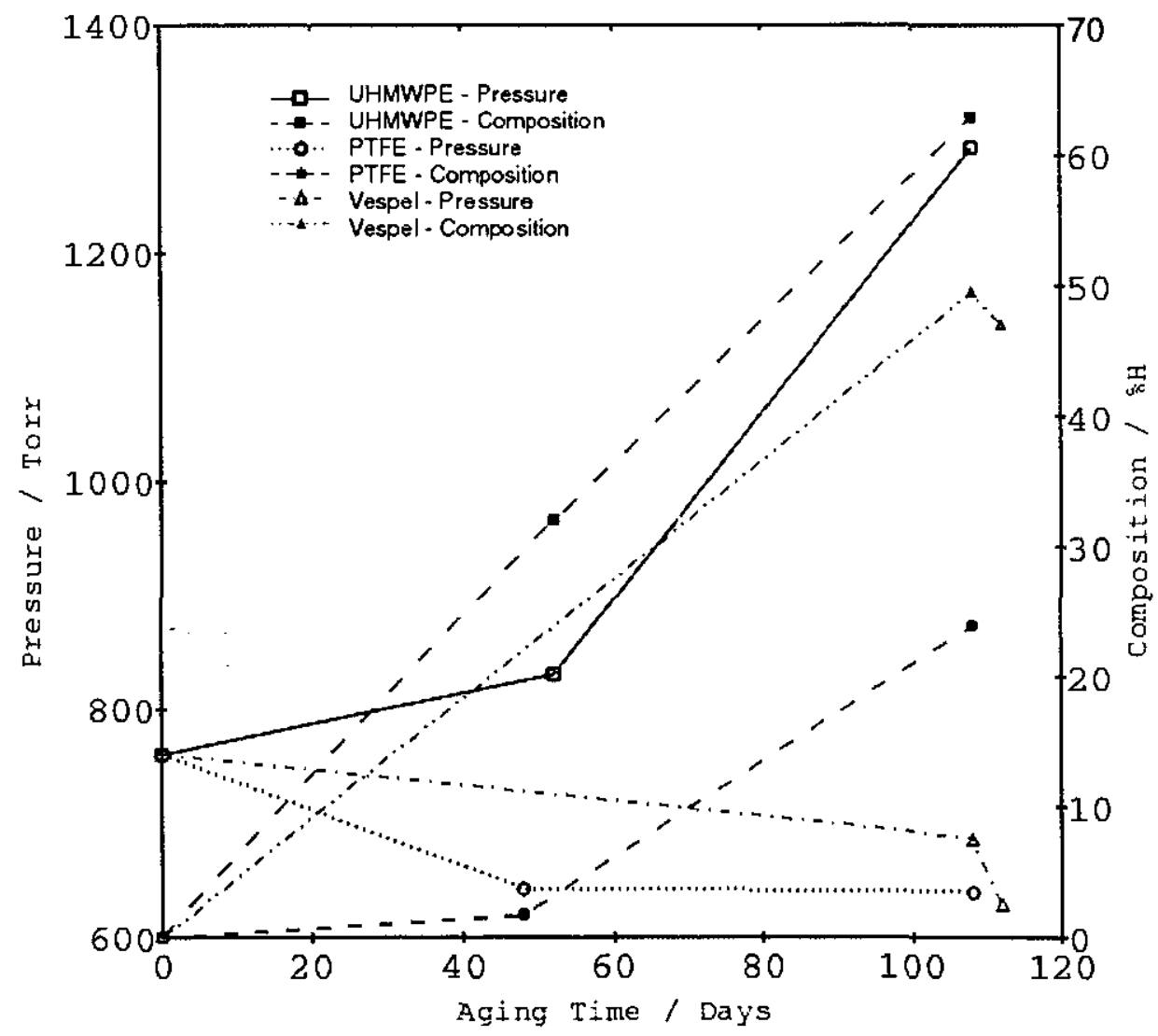

Figure 14. Computed sample cell pressure (torr) and measured cell hydrogen content (volume $\%$ of total gas) versus aging time (days). Pressure on left axis, using unfilled symbols. Composition on right axis using filled symbols. UHMW-PE - squares, PTFE - circles, Vespel ${ }^{\circledR}$ - triangles. 